\title{
Factors Influencing Good Governance in Forest Management and Protection: A Case Study of Mt. Elgon Forest Reserve, Kenya
}

\author{
Gatama Stella Muthoni Omondi Stephen Fredrick \\ Kenya Forestry Research Institute, P.O Box 201412-00200, Nairobi
}

\begin{abstract}
Despite the socio-economic and environmental benefits of forests globally, these ecosystems have been degraded due to poor governance. Effective governance in the forest sector calls for the identification of concrete elements within the administrative sector by systematically analysing the current situation and direct efforts towards improving the systems. A functional governing system would promote positive changes and progress by identifying challenges and gaps and come up with guidelines geared towards strengthening global co-operation. Our study explored the various factors influencing effective governance in forest management and protection in Kenya, using the case of Mt. Elgon Forest Reserve. Purposive sampling design was used to collect data through structured questionnaires and interactive interviews among forest managers, forest adjacent communities and other relevant stakeholders. The study shows that majority of the local communities living adjacent to the forest have been sensitized about forest conservation, however, the capacity building did not entail technical forestry operations. This has hampered effective involvement of the communities in forest management. Majority of the forest management staff are well trained in forest management and therefore could implement sustainable management strategies, however, due to insufficient fund, these strategies could not be fully implemented. Most of the members of the local communities are not economically empowered and mainly derive their livelihood from the forest leading to overexploitation. This strains sustainable utilization of the forest resources. Cultural practices such as livestock grazing and living within the forest are hampering sustainable management of the forest. The study suggests that successful management of the forest is limited by inadequate involvement of local communities. This has led to apathy and degradation of the forest by members who feel that their views are not sort in the management of the forest. The study recommends multi-sectoral planning and representation of sectors involved in forest management and conservation
\end{abstract}

Keywords: participatory forest management, forest adjacent communities, forest products, sustainable forest management

DOI: $10.7176 / \mathrm{JESD} / 11-12-06$

Publication date:June 30th 2020

\section{Introduction}

Forests provide diverse goods and services that support both biotic and abiotic elements of the environment; however, sustainable management of these resources remains a big challenge (Long, 2013). Furthermore, the forest sector has experienced numerous challenges globally over the recent decades resulting to changes in environmental landscapes as well as the social and economic status of many countries. These changes have forced countries to respond in diverse ways to promote sustainable development and management of natural resources (Wingqvist et al., 2012). One of the key concepts that will lead to the achievement of sustainable development is through good governance that seeks to provide an enabling environment for the involved people (Bosselmann et al., 2008). For example, the concept of forest governance provides a comprehensive framework of how forest-related activities are undertaken by a wide range of stakeholders for the purpose of sustainably managing forest resources and ecosystems (Agrawal, 2007). Ideally, forest governance encompasses people, procedures, rules, regulations, public and private organizations through which decisions relating to forest managements are made (Davis et al., 2013).

Majority of rural societies in developing countries depend on natural resources as their main source of livelihood, however, these societies are vulnerable due to the risks of depletion and degradation of resource base (Wingqvist et al., 2012). Clearing of forests for agriculture, overgrazing in forests, mining, inadequate operational policies and information on importance of forests are key issues that require utmost consideration for good governance and sustainable utilization of forest resources.

Kenya's forest sector has experienced poor governance in the past, and improving the situation has been an implicit objective in recent forest sector reforms (Ministry of Environment and Natural Resources, 2016). For example, the forest tenure reforms introduced with the Forests Act (2005) embraced the concept of participatory forest management, through the engagement of forest adjacent communities and the promotion of private investment. This enables private sector and community involvement and investment in commercial forestry in gazetted forest reserves, and promotes community-based forest management (Forest Act, 2005). The paradigm shift has led to concomitant institutional and organization changes, such as the establishment of the Kenya Forest Service (KFS), and the formation of Community Forest

Associations (CFAs).The Forests Act, 2005 has transformed forest management by upholding the principles 
of public participation in natural resource management.

Despite the progressive legislations and legal frameworks, forest cover in Kenya has declined drastically over the years, and this has contributed to the negative adverse effects of climate change. There is need to improve forest governance for the purpose of ensuring that forest cover is increased mainly through afforestation and reforestation (Kenya Forest Service, 2018) as well as minimize the rate of deforestation. For example, the national reserve on the Kenyan side of Mt. Elgon covers only a small area of the forest, with the rest of the forest being under the management of the Kenya Forest

Service or managed as Trust land under the County government (Kenya Forest Service, 2018). Effective management of such ecosystems requires good governance strategy that brings together the entire stakeholders.

However, in adequate collaboration among stakeholders is reported and this has led to wanton destruction of the forest (Kenya Forest Service, 2018). For example, General Forest License (GFL) is issued single handedly by KFS for extraction of major forest products such as sawn timber, pulpwood and large quantities of firewood despite the impacts to the other stakeholders (Kenya Forest Service, 2018). Ineffective governance on the Kenyan side of Mt. Elgon has led to encroachment on the forest reserve emanating especially from the Non-Residential Cultivation (NRC) areas (Kenya Forest Service, 2018). This has led to unclear boundaries between the cultivation areas and indigenous forest. Furthermore, much of the area set aside for non-residential cultivation has been completely converted into agricultural lands, where trees have been cleared and none is planted (Kenya Forest Service, 2018).

Other challenges experienced in the governance of Mt. Elgon forest include the widening imbalance between production and consumption of forest product as demand exceeds supply and production. There is rampant conversion of forest land for human use such as agriculture and settlement. The other important factor is inadequate or ineffective policies on reforestation and rural participation in forestry governance (Public Participation in Forestry in Europe and North America, 2000). In addition, there is insufficient information on the quantity, quality and growth trends of the forest, inadequate funding from the national government in the environment sector, conflict of interests among different lumbers and priorities in the management of Mt. Elgon forest (Maginnis, 2007).

In order to realize the importance of good governance in the forest sector, there is need to identify concrete elements within the administrative sector by systematically analyzing the current situation and direct efforts towards improving the systems (CIPFA, 2012). A functional governing system would promote positive changes and progress by identifying challenges and gaps and come up with guidelines geared towards strengthening global co-operation (CIPFA, 2012). The aim of the present study was to determine factors influencing governance of Mt. Elgon forest with a view to recommend measures that will promote good governance in the forestry sector. The following questions were answered during the research: a) How empowered is the forest workforce and community towards management of Mt. Elgon forest? b) Which economic factors influence governance of Mt. Elgon forest? c) Which social factors influence governance of Mt. Elgon forest? d) Which cultural factors influence governance of Mt. Elgon forest? e) Which measures can be implemented to enhance good governance of Mt. Elgon forest?

\subsection{Materials and Methods}

\subsection{Study Area}

The study was carried out in Mt. Elgon forest reserve, which lies in the Western part of Kenya.

Mt. Elgon forest reserve is the fourth highest (4321 m) solitary volcanic mountain in Africa that covers 73,706 ha of land and consists of upper montane forest found between $3050 \mathrm{~m}$ and $3300 \mathrm{~m}$ above sea level, bamboo forest between $2450 \mathrm{~m}$ and $3050 \mathrm{~m}$ above sea level, dry lower montane forest between $2000 \mathrm{~m}$ and $3050 \mathrm{~m}$ above sea level and moist lower montane forest between $1500 \mathrm{~m}$ and $2450 \mathrm{~m}$ above sea level (Hitimana et al., 2010). The mountain is shared between Kenya and Uganda, which is separated by the 'Mt. Elgon National Park. The national park covers $22 \%$ of the land area and attracts tourists to view diverse species of wildlife, vegetation as well as attractive landscapes which in turn contributes to the economic development of the country (Hitimana et al., 2010).

Mt. Elgon forest reserve has been selected as the case study for the research because the region has experienced tensions emanating from eviction of indigenous communities from the forestland to allow for conservation and afforestation. In order for the government to successfully implement policies geared towards conservation and afforestation, it is paramount to benchmark the policies on factors that influence good governance in forest management and protection. Mt. Elgon forest is therefore a suitable case study area for determining the factors that influence good governance in forest management and protection.

\subsection{Study Design}

We used purposive sampling technique to select the respondents for this study. The respondents were purposively selected because they were in a better position to provide information on factors influencing good governance of Mt. Elgon forest reserve due to their interaction with the forest and/or administrative responsibilities. The target population comprised of officials in the Kenya Forest Service, Kenya Wildlife Service, Non-governmental organizations dealing with conservation of Mt. Elgon forest and community members. 
The research utilized qualitative research method since the main aim was to recommend measures that will promote good governance in the forest sector thus the use of qualitative method with the use of interviews and interview guides. This was enhanced by consulting widely on secondary data and other information that was deemed to have a strong correlation to the study.

Interviews were used due to the fact that respondents can feel free in the interview; they are more probable to open up and share what they really mean and are more probable to provide valid data (Edwards and Holland, 2013). Through this, the researcher had more chance to gather a wide range of information and ask the interviewee to qualify and develop their answers. Document review was also undertaken to provide comprehensive information.

\subsection{Data Analysis}

We used an exploratory or conceptual content analysis process for the qualitative data. This was more ideal because the information was gathered from the interview guides that contributed to identifying the management issues related to forest governance.

\subsection{Results and Discussions}

\subsection{Empowerment of the Communities at Mt. Elgon Forest}

The Ministry of Forestry and Wildlife report shows that area under forest cover increased from $710.23 \mathrm{~km}^{2}$ to $777.70 \mathrm{~km}^{2}$ from the year 1985- 2010 due to increase in awareness by the communities on shamba system and on the importance of forest regeneration (Ministry of Forestry and Wildlife, 2013). From the present findings, it is evident that the community members living adjacent Mt. Elgon forest reserve have been trained on forest management by professional bodies such as Kenya Forest Service (KFS). The training has empowered the community member by enhancing their skills in sustainable utilization of the forest products. The community members' ability to effectively participate in forest conservation has also enhanced (Larson et al., 2008). As a conservation strategy, the forest adjacent community members were provided with free tree seedlings to plant on their farms, which they could use after maturation for provision of their diverse needs including financial returns (Robson, 2007).

This strategy eventually boosts the social, economic and environmental aspects of the region. The study shows that about $29 \%$ of the respondents have heard about governance in forest management from print media (newspaper) and electronic media (television or radio programs). However, a majority of the respondents $(71 \%)$ said they have not attended any educational programmes (short courses, field tours, seminars, conferences, etc.) related to the management of forest land.

In our study, it was evident that community members living around Mt. Elgon forest reserve have been sensitized on the importance of conserving natural resources (Robson, 2007). This has been enhanced through capacity building strategies such as provision of incentives to ensure that the limited resources are utilized sustainably to ensure that future generations have access to these resources (Medina et al., 2009). In order to meet their needs such as provision of clean water for the households, sanitation and domestic use, $90 \%$ of the respondents have been empowered through sensitization on the importance of water harvesting. This is by use of boreholes, man-made dams and gutters that collect rain water from roof tops (Ostrom, 1990). However, the remaining $10 \%$ of the respondents still depend on the seasonal rivers for water supply. The study suggests that it will be important if the sensitization could also reach the minority groups adjacent to the forest reserve for successful adoption of conservation skills and knowledge within the area (Medina et al., 2009). This will bring the sense of ownership among the community members.

\subsection{Empowerment of the Forest Workforce at Mt. Elgon Forest}

Majority of the staff $(95 \%)$ in the forest management had the same point of view in regard to training of forest workforce on forest management. All the forest management staff have had professional training; however, more empowerment is required. They mentioned the required categories of training programmes that consisted mainly of; site/land preparation for new trees, planting of new trees, thinning, pruning, application of herbicides, pesticides or fertilizers, control of exotic tree species, maintenance of roads in the forests, restriction of public access, prevention and management of forest fire and prescribed burning (Christodoulou, 2001). These may come in mainly as refresher courses.

\subsection{Economic Factors Influencing Governance of Mt. Elgon Forest}

The study established that governance of Mt. Elgon forest reserve is influenced by the economic status of the communities living adjacent to Mt. Elgon forest reserve, availability of funds to undertake routine management activities, financial management strategies and policies, government forest sector funding, economic efficiency, equity and incentives (Dev et al., 2003). About $20 \%$ of the respondents were mainly herders while $80 \%$ of the residents of Mt. Elgon forest reserve were mainly peasant farmers who grow food crops like maize and beans for household consumption leading to low income generation. The low economic status of the residents adjacent to 
Mt. Elgon forest reserve has negatively impacted on forest governance due to overdependence on forestry resources (Taylor, 2010). Many residents living adjacent to the forest reserve do not have many options of income generation outside the forest, hence increasing pressure on the resources within the reserve (Agrawal and Chhatre, 2006). In addition, as a result of low economic status, many residents are unable to afford other sources of fuel that are costly rather than firewood that is easily obtained from the forest.

The interview generated a number of products obtained from the forest which include: fuel wood (firewood and charcoal) construction materials (timber, poles, posts, rafters, withies, ropes, thatching grass), fodder (pasture), medicinal herbs (traditional medicine) and food (produce of non-residential cultivation, wild honey, vegetables and bamboo shoots). The benefits of these forest resources to the people are at the very subsistence level (Antinori and Bray, 2005). It has not been easy to observe equity concerning the allocation of these benefits to the society; consequently, frequent disagreements on sharing of the forest resource products undermine the integrity of those mandated with the governance of the forest (Agrawal and Chhatre, 2006).

\subsection{Socio-Cultural Factors Influencing Governance of Mt. Elgon Forest}

Eighty-eight percent $(88 \%)$ of the respondents mentioned that integrity and ethics have been lacking in the management of Mt. Elgon forest reserve. Particularly, they have experienced shortcomings in the area of transparency, openness and accountability in harvesting as well as poor supervision of utilization of forest and forest products resulting in conflicts of interests over forest resources and allocation of land among the indigenous communities (Agnoletti, 2014). The findings correspond to the previous studies on governance whereby the authors argued that citizens should be put on the forefront when it comes to decision making processes that will affect them (Denhardt and Denhardt, 2000). This is not necessarily by letting them lead the relevant authority but by taking neutral grounds that will incorporate both the government demands and the citizens' needs. This involves understanding the citizens' needs before making decisions. This may be critical in the overall outcome of forestry governance, which may be affected by the community participation as they are the key beneficiaries of these natural resources (Denhardt and Denhardt, 2000). 'Values such as efficiency and productivity should not be lost, but should be placed in the larger context of democracy...' and thus good governance will be achieved (Ongaro, 2006). Lack of 'transparency' and 'social accountability' contributes to bad governance which is unsustainable hence there is need to identify the negative characteristics that affect good governance and eliminate them completely or identify mitigation measures (Ongaro, 2006).

Communities living adjacent to Mt. Elgon forest reserve, consist mainly of Sabaot, Iteso and Bukusu ethnic groups, who are agriculturalists (KARI, 2006) and consists of $80 \%$ of the population and the Ogiek who are the minority consisting of $20 \%$ of the population practicing pastoralism as a way of living (KARI, 2006). The Ogiek keep cattle and goats within their homestead but also practice bee keeping within the forests. The Ogieks' traditions have been passed on through generations and hence the members have been taught the importance of conserving trees. The conservation promotes the growth of grass and through the tree branches; beehives are mounted to promote the production of honey from bees (Agnoletti, 2014). The honey is then sold within the neighbourhood thus supporting the economic status and the well-being of the communities. Honey is also used locally for curing ailments.

Incorporating socio-cultural factors within forest management and protection will contribute towards promoting good governance among regions. Indigenous people are believed to have acquired indigenous knowledge on protection of biodiversity, ecosystems and culture over the years, (KARI, 2006) which has been passed down generations and this can produce positive results within the forestry sector through conservation and protection. Moreover, the female gender in the rural communities are believed to have direct contact with the environment in their day to day activities such as collection of firewood in the forest and have still managed to maintain them for their future use (Agnoletti, 2014). Through them, traditional knowledge can be acquired on how to protect forests while benefiting from them and this will enable future generations have access of forests and its resources.

\subsection{Community Participation in Forest Management}

In spite of efforts by KFS to involve communities in the management and sustainability of forests, communities at Mt. Elgon feel that they are not fully engaged in KFS programmes. About $88 \%$ of the respondents stated that disconnection between KFS policies and community participation mainly results from lack of policy customization (Berkes, 2007). The residents of Mt. Elgon forest reserve claimed that they are not involved in decision-making processes that are leading to formulation of policies (Taylor, 2010). Therefore, the residents lack sense of ownership of the processes and are reluctant to actively participate in the implementation. However, $20 \%$ of the respondents acknowledged that policies have guided the community decisions in regard to forestry while $2 \%$ had no idea of the existence of policies (Jashimuddin and Inoue, 2012). 


\subsection{Conflict Management}

Conflict management influences forest governance in Kenya specifically, resolution of conflicts between residents and wildlife, residents and government institutions and amongst communities living adjacent to the forest (KFS, 2018; FAO, 2013). The main reason for unsuccessful conflict resolution is inadequate identification of root causes of the source of problems and thus there is need for drafting a conflict management system that will assist in solving conflicts at an early stage before they progress and become more complex and difficult to solve (FAO, 2013; FAO, 2011)

Human-wildlife conflict issues were raised by most of the farmers who complained that wildlife have been encroaching farmlands and end up destroying their food crops, fences and even killing their livestock and goats. This has even gone to an extent of the wildlife attacking some of the community members and game wardens who end up with massive injuries while others end up losing their lives. As a result, community members end up hunting and killing the wild animals in order to protect themselves as well as their livestock and property (Conover, 2002).

\subsection{Conclusion and Recommendations}

The study concludes that governance within the forest sector in Kenya is steered by a confluence of economic, social, cultural and regulatory factors. The main economic factors influencing governance of forest in Kenya are economic status of the communities living around forests, availability of funds for reforestation and afforestation and financial management. Social factors include community participation in forest management, conflict management, integrity and ethics which encompass transparency, honesty and truthfulness, openness, accountability, zero tolerance to corruption, commitment to service delivery, disclosure of interest, efficiency and effectiveness (KFS, 2009). Cultural factors include cultural conflicts, cultural erosion and fundamentalism/traditionalism. Regulatory framework also plays a key role in the governance of forest sector through the establishment of rules and regulations within the governing system by forming the fundamental structure of the legal framework (KFS, 2009).

The study recommends multi-sectoral planning and representation (KFS, 2009) of sectors involved in forest management and conservation. This will assist in representing various stakeholders involved in forestry related activities within the forestry committee as well as promote members to network and gain diverse ideas on how to arrest further forest destruction. Through systematic approach and representation of various governing institutions will lead to problem identification learn and understand their functions making them more responsible and minimizing parallel programmes that may lead to conflicts (KFS, 2009). Moreover, communities will be empowered through representation in the committees and sustainable decisions will be achieved through inclusion of their ideas within the decision making process.

\section{Data Availability}

The datasets generated during and/or analysed during the current study are available from the corresponding author on reasonable request.

\section{Conflicts of Interests}

The authors declare that they have no conflict of interest

\subsection{References}

1. Long, A. (2013). REDD ${ }^{+}$, Adaptation, and sustainable forest management: toward effective polycentric global forest governance. Tropical Conservation Science. Special Issue, 6(3), 384-408.

2. Wingqvist, G., Drakenberg, O., Slunge, D., Sjostedt, M. and Ekbom, A. (2012). The Role of Governance for Improved Environmental Outcomes: Perspectives for Developing Countries and Countries in Transition. The Swedish Environmental Protection Agency: Sweden, Stockholm.

3. Bosselmann, K., Engel, R. and Taylor, P. (2008). Governance for Sustainability: Issues, Challenges, Successes. Gland (Switzerland): International Union for Conservation of Nature.

4. Agrawal, A. (2007). Forests, Governance, and Sustainability; Common Property Theory and its Contributions. International Journal of the Commons 1(1):111-136.

5. Davis, C., Williams, L., Lupberger, S. and Daviet, F. (2013). Assessing Forest Governance: The Governance of Forest Initiative Indicator Framework. USA, Washington, DC: World Resource Institute.

6. Ministry of Environment and Natural Resources. (2016). National Forest Programme of Kenya, MENR, Nairobi, Kenya.

7. Forest Act, (2005). Forest Act 2005. Government of Kenya.

8. Kenya Forest Service. (2018). Laws that Protect our Forests: The Forest Conservation and Management Act 2016.

9. Public Participation in Forestry in Europe and North America. (2000). International Labour Office. Geneva.

10. Maginnis, S. (2007). Forest Law Enforcement and Governance as a Means to Support SFM: IUCN: Forest 
Program.

11. The Chartered Institute of Public Finance and Accountancy (CIPFA). (2012). Delivering Good Governance in Local Government. London: CIPFA.

12. Hitimana J., Kiyiapi, J., Nhunge, J. and Bargerei, R. (2010). Disturbance Indicators and Population Decline of Logged Species in Mount Elgon Forest: Kenya: Moi University Eldoret.

13. Edwards, R. and Holland, J. (2013). What is Qualitative Interviewing? Bloomsbury Plc London UK and New York USA.

14. Analysis of drivers and underlying causes of forest cover change in the various forest types of Kenya. (2013). Ministry of Forestry and Wildlife.

15. Larson, A., Barry, D., Cronkleton, P., Pacheco, P. (2008). Tenure Rights and Beyond: Community Access to Forest Resources in Latin America; CIFOR Occasional Paper No. 50; CIFOR: Bogor, Indonesia.

16. Robson, J.E. (2007). Local approaches to biodiversity conservation: lessons from Oaxaca, southern Mexico. Int. J. Sust. Dev., 10, 267-286.

17. Medina, G., Pokorny, B. and Campbell, B. (2009). Community forest management for timber extraction in the Amazon frontier. Int. For. Rev., 11. 408-420.

18. Ostrom, E. (1990). Governing the Commons: the Evolution of Institutions for Collective Action; Cambridge University Press: London, UK.

19. Christodoulou Al. (2001). The Contribution of Forests and Forestry in Rural Development. Ministry of Agriculture, Natural Resources and Environment, Forestry Department. Cyprus.

20. Dev, O.P., Yadav, N.P., Springate-Babinksi, O. and Soussan, J. (2003). Impacts of community forestry on livelihoods in the middle hills of Nepal. J. For. Liv, 31, 64-77.

21. Taylor, P.L. (2010). Conservation, community, and culture? New organisational challenges of community forest concessions in the Maya Biosphere Reserve of Guatemala. J. Rural. Stud. 26, 173-184.

22. Agrawal, A. and Chhatre, A. (2006). Explaining Success on the Commons: Community Forest Governance in the Indian Himalaya. World Dev., 34, 149-166.

23. Antinori, C. and Bray, D.B. (2005). Community forest enterprises as entrepreneurial firms: Economic and institutional perspectives from Mexico. World Dev. 33, 1529-1543.

24. Agnoletti, M. (2014). Environmental Thinking and Cultural Values: a reflection on environmental globalisation and the Mediterranean Culture. Global Environment 7:257-290

25. Denhardt, J.V. and Denhardt, R.B. (2000). The New Public Service: Serving rather than Steering: US: Arizona State University.

26. Ongaro, W. (2006). Good Governance and Poverty Reduction Measures: The Case Study of Kenya. Vol. 4 No. 3.

27. Kenya Agricultural Research Institute (2006). Indigenous Peoples Plan: Kenya Agricultural Productivity Sustainable Land Management Project.

28. Berkes, F. (2007). Community-based conservation in a globalized world. P. Natl. Acad. Sci, 104, 1518815193.

29. Jashimuddin, M. and Inoue, M. (2012). Community Forestry for Sustainable Forest Management: Experiences from Bangladesh and Policy Recommendation. FORMATH, 11: 133-166.

30. Food and Agriculture Organizations (2013). Collaborative conflict management for enhanced national forest programmes. Training Manual. National Forest Programme Facility, FAO.

31. Food and Agriculture Organizations (2011). Collaborative conflict management for enhanced national forest programmes. National Forest Programme Facility, FAO.

32. Conover, M. (2002). Resolving human-wildlife conflicts: the science of wildlife damage management. Lewis Publishers, New York.

33. Kenya Forest Service. (2009). The Kenya Forest Service Strategic Plan, 2009/10- 2013/14. Kenya Forest Service, Nairobi 